\title{
Development and Testing of Intelligent Alcohol Transportation Security System
}

\author{
Velaphi Msomi $(\mathbb{D})$ and Shandene E. A. Solomons \\ Mechanical Engineering Department, Engineering Faculty, Cape Peninsula University of Technology, P.O. Box 1906, \\ Bellville 7535, South Africa \\ Correspondence should be addressed to Velaphi Msomi; msomiv@gmail.com
}

Received 16 November 2017; Revised 6 February 2018; Accepted 18 February 2018; Published 20 March 2018

Academic Editor: Aboelmaged Noureldin

Copyright ( 2018 Velaphi Msomi and Shandene E. A. Solomons. This is an open access article distributed under the Creative Commons Attribution License, which permits unrestricted use, distribution, and reproduction in any medium, provided the original work is properly cited.

\begin{abstract}
The development and testing of intelligent liquid transportation security system are being reported in this paper. The targeted fluid to be secured was ethanol alcohol and this was due to the theft cases occurring during the transportation of this product from the supplier to the customer. The system was developed such that only the radar level sensor (VEGAPULS 62) might be in contact with the fluid and the rest of the system remained outside the liquid carrying container to be secured. The system was developed such that it reports any abnormal liquid level drop through short message service (SMS). The functioning of the developed system was tested through the use of 1040 L Intermediate Bulk Container (IBC) filled with water which was hauled for about $1.5 \mathrm{~km}$. The liquid theft was simulated and the system sent two SMS. The first SMS reported the beginning of water level drop and the second one reported the ending of water level drop. The second SMS reported the amount of liquid that was taken out of the container.
\end{abstract}

\section{Introduction}

Transportation of bulk goods forms a large part of the economic sector. Logistic companies have large fleets carrying goods to various destinations. Whilst these operations can be controlled on-site, once in transit it becomes difficult to monitor the goods being carried leaving them vulnerable to theft. Many tracking system solutions have been developed but most of them were designed to monitor the quality of the solid food being transported [1]. These food quality monitoring systems detect the presence of various gases which might be threat to the quality of food inside the packages. They do not provide the quantity being monitored during the transportation. Oil and gas industries are the ones which have done work on leak detection and monitoring during transportation [2]. It should be noted that the mostly used oil and gas transportation mode is the underground pipe system. Alkhaledi et al. [3] presented gas leak detection system called fault tree analysis and this technique identifies the exact point of leakage. Elaoud et al. [4] developed an oil leakage detection technique which is based on transient negative pressure waves. Scott and Barrufet [5] developed a complex method which uses real-time transient model to detect the small pipes leakages. Real-time pipeline leak detection method based on volume balancing was developed by Doorhy [6]. The method has capabilities to detect small pipeline leakages but it takes considerable time to detect them.

The monitoring systems employed in oil and gas industry deal with fluid loss which affects the economy. The objective of developing and employing such systems is to maintain the quality and the quantity of goods being transported. It is based on this objective that the oil and gas based literature is included in this work because it relates to the objective that this work is trying to achieve. This paper reports on the development and testing of the intelligent liquid monitoring system for road transportation mode. The targeted liquid to be secured is ethanol alcohol. The objective of developing such system is to eliminate or reduce theft of this product occurring during its transportation. The system is designed such that it monitors liquid level during transportation. It has a capability to report the amount of liquid taken out of the transporting container. The system reports to the supplier through short message service (SMS). All the SMS sent to the 
supplier get duplicated and stored to the server that can be accessed by the supplier. This duplication of SMS serves as a backup in case of cellphone theft or damage.

\section{Solution Specifications}

In general, the development of a system has to meet certain specifications; hence this section is included.

The development and the implementation of any safety device require that the developed device must comply with certain standard to avoid problems. There are number of explosion proof design standards available commercially which evaluate the explosiveness of the devices or systems being developed [7]. All the components used in constructing our system were evaluated for their explosiveness, that is, looking at the explosive temperature for each component against the explosive range specified by Jespen [7]. Tank level was the critical variable to be measured as it was the focal key performance indicator (KPI) of this work. Various container configurations exist which means the system had to be flexible to accommodate different configurations and sizes. The level sensor to be used for this application had to be biocompatible and not reactive since the targeted liquid to be secured was for human consumption. The level sensor had to provide real-time continuous readings even if the liquid quality and temperature vary. System location point on the carrying container and the system casing were also the critical factors as they had an impact on satellite connectivity. Power failure backup was also a requirement for our system. The battery system was used as power backup plan in case of the main power supply failure.

\section{Methodology}

This section describes all the steps followed in the construction of the system such that the objectives described in the solution specification are satisfied. The system was constructed through the following major components.

3.1. Radar Level Sensor (VEGAPULS 62). The VEGAPULS 62 level sensor is a noncontact sensor which uses microwaves to detect the level of the liquid. It is designed to measure different types of liquid and does not react with the measured liquid. The maximum measuring range of this is $38 \mathrm{~m}$. The sensor can operate under a very harsh environmental condition, that is, temperature range of $-196^{\circ} \mathrm{C}$ to $450^{\circ} \mathrm{C}$. More specifications could be found on the sensor specifications sheet.

\subsection{Siemens LOGO! CMR2040. LOGO! CMR2040 is the} electronic device which is used for wireless communication. CMR is an abbreviation of communications module radio. The satellite and the sensor information captured by LOGO! CMR2040 got monitored through S7-1200 programmable logic controller (PLC). S7-1200 PLC is a device used in controlling decentralized system. More information about these devices is freely available from websites. The general schematic overview diagram for the connection and wireless communication is shown in Figure 1. The switch symbol in

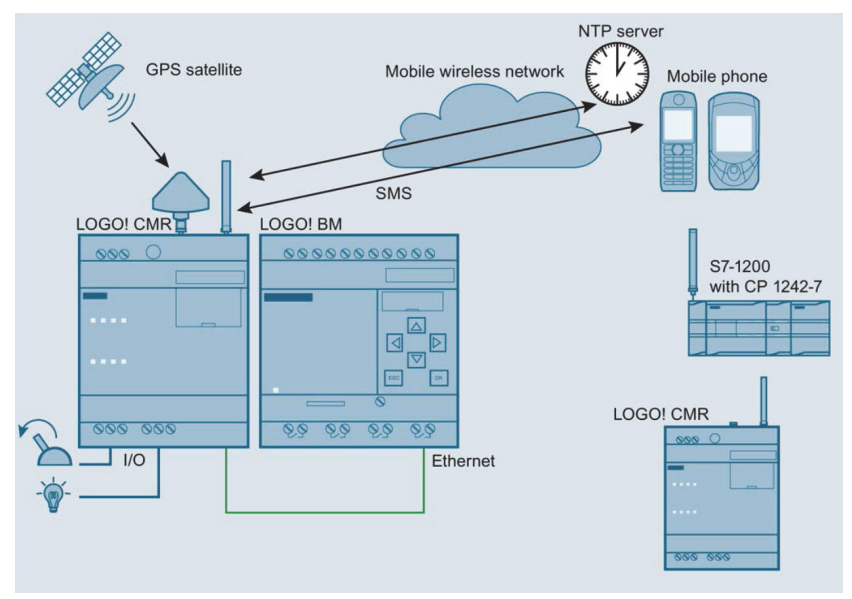

FIgURE 1: Schematic diagram for LOGO! CMR2040 wireless communication (extracted from the product manual sheet).

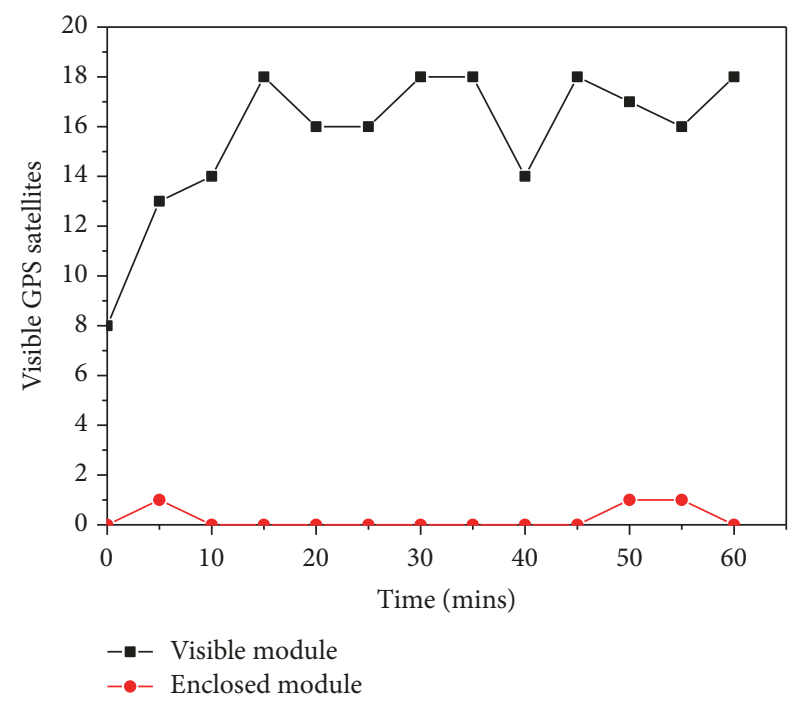

FIGURE 2: Satellite visibility over an hour.

the Figure 1 is reserved for the input signal (in our case the level sensor) whilst the bulb symbol is for activation of the notifications (like alarms or red flashing lights). The wireless communication between the system installed in the liquid carrying container and the mobile phone was through the Siemens LOGO! CMR2040 device. The receiver reads the latitude and longitude coordinates into its onboard memory in degrees, minutes, and seconds format. It also stored the altitude, signal state, and amount of visible satellites in use up to 18 (see Figure 2). This data is transferred from the LOGO! to the S7-1200 programmable logic controller (PLC) for monitoring via Profinet protocol for route referencing and liquid level monitoring.

It should be noted that the liquid carrying container dimensions need to be recorded during the input control data for accurate readings. In our case, the cylindrical configurations were used in design calculations because this is how most alcohol containers are configured. The total volume 
in the tank is calculated as a sum of all the compartment volumes. For the cylindrical section with the flat ends, the segment area representing the partial fill level can be calculated by subtracting the area of triangle from the area of a sector if it is lower than the radius [8]. If it is higher, the sector area is subtracted from the full area and the triangle area is retained. When calculating the volume for a partial fill level less than the radius of the cylinder, the segment itself represents the level and is calculated based on (1). If the partial filled level is more than the radius, the calculation of the segment follows (2). The volume is calculated simply by multiplying the partial fill area with the length of the compartment.

$$
\begin{aligned}
A_{\mathrm{sm}}= & R^{2} \arccos \left(1-\frac{h}{R}\right)-(R-h) \sqrt{2 R h-h^{2}} \\
A_{h>R}= & \pi R^{2}-R^{2} \arccos \left(1-\frac{h}{R}\right) \\
& +\left(R-h_{\text {norm }}\right) \sqrt{2 R h-h^{2}} .
\end{aligned}
$$

For the end compartments with the 2:1 elliptical heads, the cylindrical section, which includes the straight flange distance in its length, is also calculated with (1) and (2). A single head's wetted area $(S)$ is calculated using (2). It should be noted that the wetted area depends on variables $R$ and frictional liquid level $(F)$, where $F$ is calculated using (3) and $\varepsilon$ is equal to 0.866 for $2: 1$ elliptical heads.

$$
\begin{aligned}
S= & \frac{\pi R^{2}}{2}\left\{(F-0.5) \sqrt{1+12(F-0.5)^{2}}+1\right. \\
& \left.+\frac{1}{4 \varepsilon} \ln \left[\frac{4 \varepsilon(F-0.5)+\sqrt{1+12(F-0.5)^{2}}}{2-\sqrt{3}}\right]\right\} .
\end{aligned}
$$

Fractional liquid level is equal to partial fill height divided by internal cylinder diameter. The elliptical head calculation is based on (3). The cylindrical volume including the straight flange length plus the elliptical head volume gives the total volume of the compartment.

$$
V=2 R^{3} \frac{\pi}{12}\left[3\left(\frac{h}{2 R}\right)^{2}-2\left(\frac{h}{2 R}\right)^{3}\right]
$$

It was deemed necessary to check the performance of the GPS module when its antenna was enclosed inside the system encasing and when it was outside. Figure 2 shows the results for the comparison test performed between the enclosed GPS module antenna and the line of sight GPS module antenna. The purpose of enclosing the GPS module was a way of protecting the system from possible theft or damage. It is clear from the graph (Figure 2) that the idea of enclosing the system will compromise the accuracy of the feedback from the system. This suggests that there will be a lot of signal loss from the system.

The system can be operated using the user interface screen (S7-1200 PLC screen). The screen is designed to be

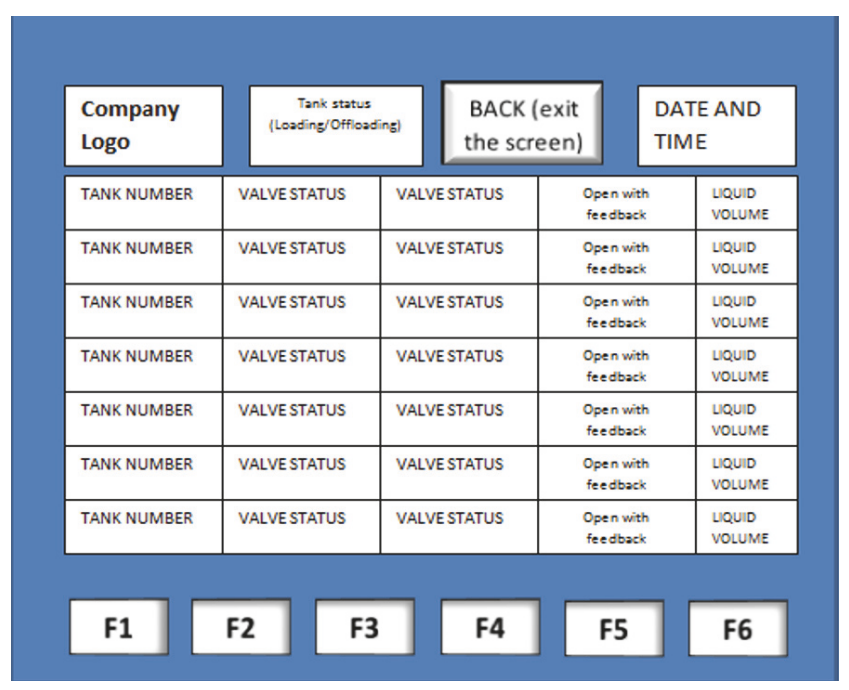

FIGURE 3: Operator interface process control.

a touch screen and the access to the screen is protected by a password. A database with all the relative client location coordinates is stored in the PLC. These variables may be configured on the system but are secure with password protection. The location of the liquid carrying container is continuously cross-referenced against the database to determine whether it is in range of a stored location. Once the tanker is in a range, the system will set the location as active. Since the earth is an oblate spheroid, the distance between two points on earth must be measured on the surface of the sphere. Equation (4) is used to determine the large-circle distance which was useful in determining the data that could be used to locate the position of the liquid carrying container.

$$
\begin{aligned}
& d=2 r \\
& \cdot \arcsin \sqrt{\text { harvesin }(\Delta \phi)+\cos \phi_{1} \cos \phi_{2} \text { harvesin }(\Delta \lambda) .} .
\end{aligned}
$$

When one wants to access data for the system through screen shown in Figure 3, one-time pin (OTP) needs to be used. The user receives an SMS with OTP and its expiry information (see Figure 4). Upon successful entry of the OTP, the user may then access the process control functions where the valves can be controlled for filling and offloading (see Figure 3).

The control system contains two 12 VDC $12 \mathrm{Ah}$ batteries as backup supply to continue powering the unit even if the main supply is cut. This allows monitoring of the main power supply using a current transducer to measure the current drawn and a diode ensuring that the current from the batteries does not flow backward to the main power supply. The logic controller and its communications module need to be powered so as to send notification of a loss of power from the truck whilst on route and ensure all the compartment levels are being monitored. If in battery mode whilst out of range of a saved location, the system sends an SMS notification. The control panel door is monitored by a proximity sensor to check if the enclosure's door has been opened which will allow for disconnection of power to the controllers. If so, an SMS notification is also sent. 


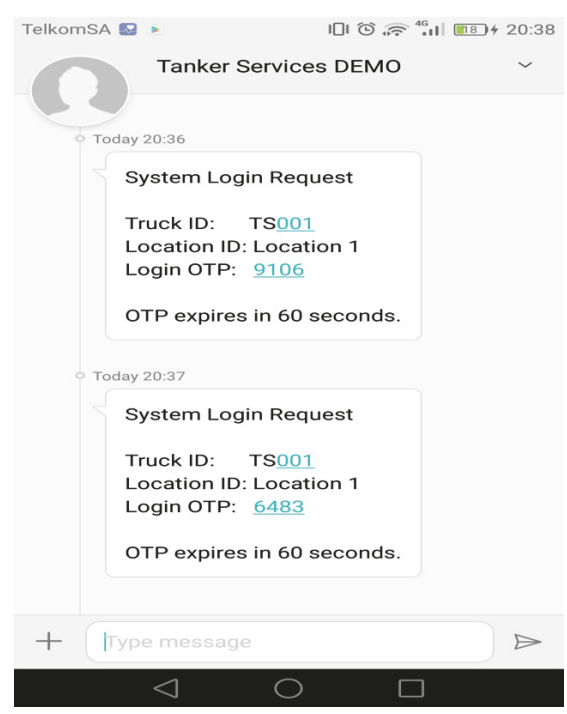

FIGURE 4: One-time pin SMS notification.

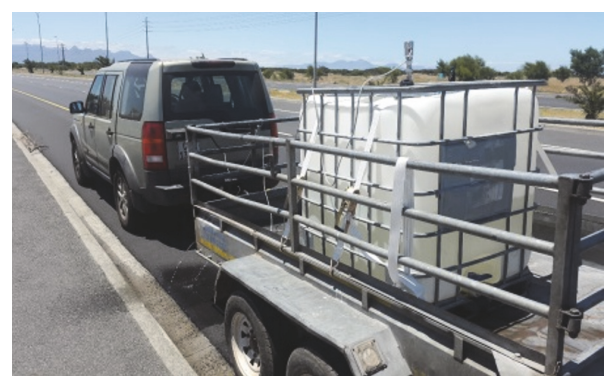

FIGURE 5: System installation test.

\section{Results and Discussion}

This section is looking at the performance of the system when it is installed. For the purpose of testing the system, a 1040liter IBC filled with water was placed on a trailer and hauled for about $2 \mathrm{~km}$ to test the reading stability (see Figure 5).

The filling up of the container profile gets recorded and stored in the server which can be accessed by the supplier. Figure 6 shows IBC being filled with water for testing purposes. There are a number of crucial inputs that the system require before the filled container leaves the supplier. Those inputs include the amount of liquid in the container (indicated by yellow line), the maximum setpoint that the fluid can reach during fluctuation (purple straight line), and the minimum setpoint that the fluid can reach during fluctuation (lime straight line). The liquid fluctuation is assumed to be emanating from the unevenness of the road surface when the vehicle carrying liquid is in motion. Figure 7 shows the liquid level fluctuation with two sharp peaks resulting from excessive vehicle breaking. The liquid level fluctuation became a problem in accurately monitoring the level drop and hence the introduction of averaging function block which was programmed through PLC. The dampening of the erratic instantaneous readings is shown in Figure 8.

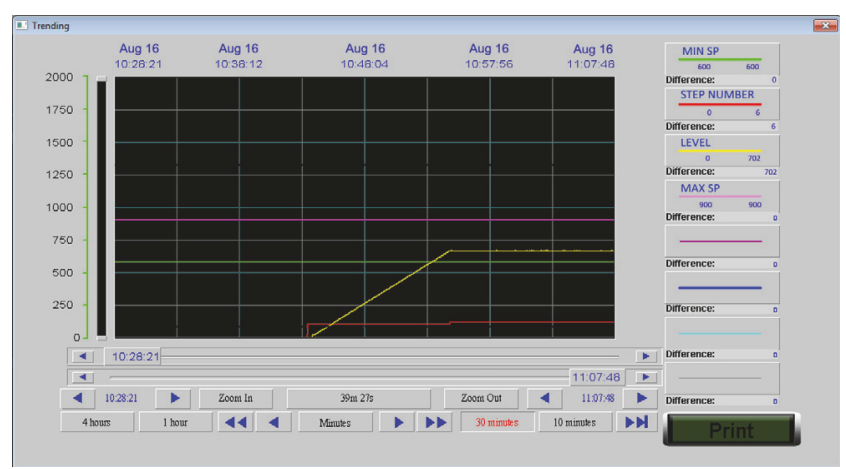

FIGURE 6: IBC filling up profile.

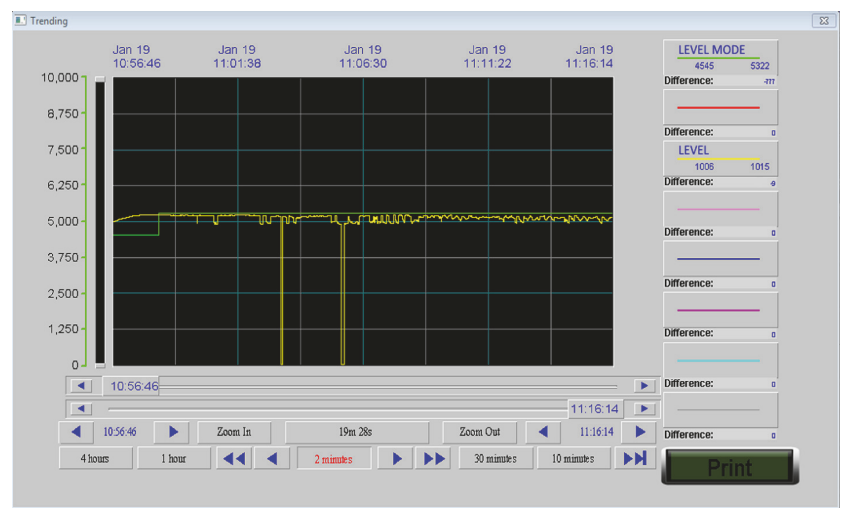

FIgURE 7: Instantaneous liquid level readings.

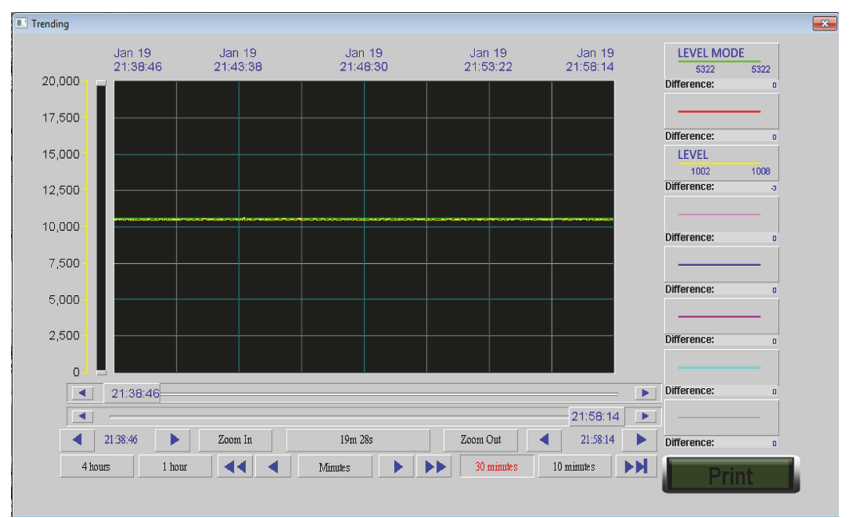

FIGURE 8: Dampened liquid level fluctuation readings.

Figure 9 demonstrated the simulation of the abnormal liquid level drop. The yellow line shows the emptying of the liquid from the carrying container (IBC). It should be noted that there was a stable liquid level before dropping. This indicates that the liquid carrying container was not in motion. Figure 10 is the demonstration of the SMS notification received by the supplier. The SMS carries the information about the vehicle carrying the liquid container, the GPS coordinates, and the amount of liquid inside the container. The demonstration SMS giving notification of the ending of the abnormal activity is shown in Figure 11. The second 


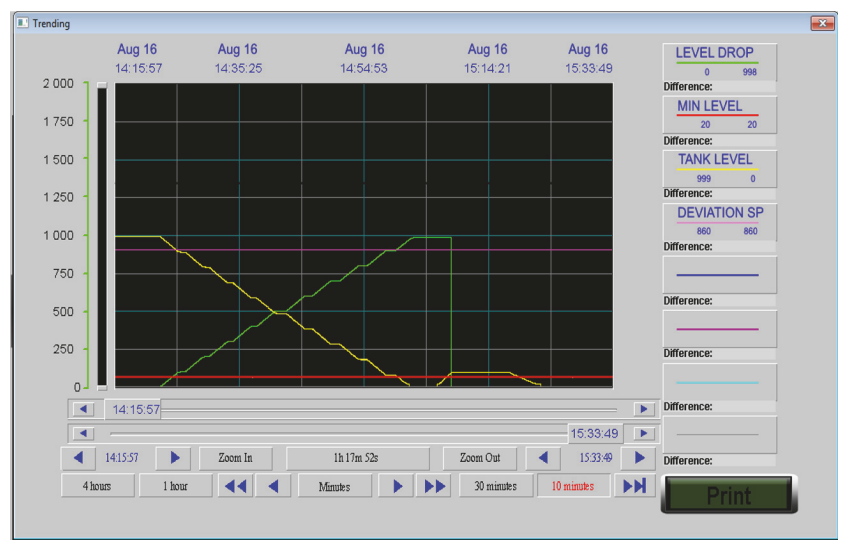

FIgURE 9: Simulation of liquid level drop.

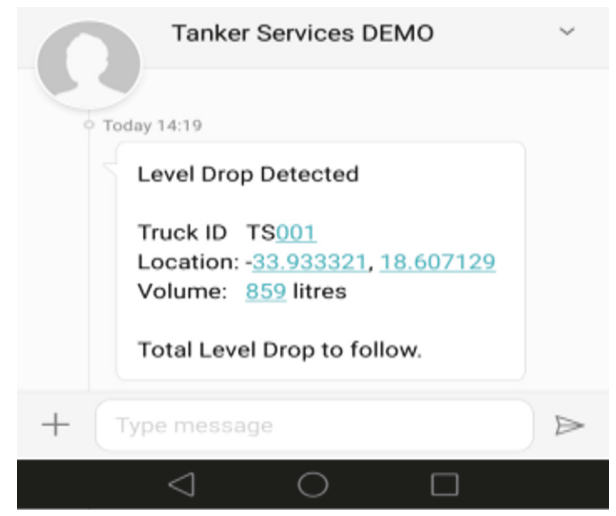

FIGURE 10: Liquid level drop detection SMS notification.

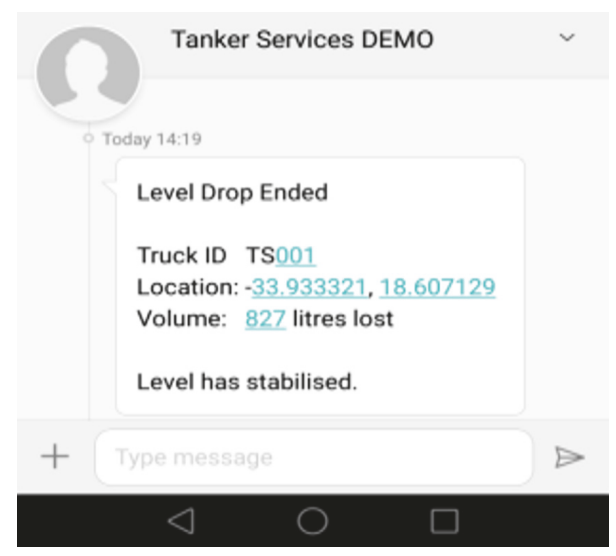

FIgURE 11: Liquid level drop detection SMS notification.

SMS records location, vehicle information, and the amount of liquid taken out of the container.

A test was done to compare the circular distance measurement (see (4)) function programmed into the PLC to a measuring wheel's distance. The results are shown in Table 1.

The haversine formula's accuracy is more than suitable for the application coming in at an average of $1.18 \%$ deviation
TABLE 1: Measuring wheel versus haversine formula.

\begin{tabular}{lcc}
\hline Measuring wheel & Haversine formula & Visible satellites \\
\hline $10 \mathrm{~m}$ & $10.38 \mathrm{~m}$ & 8 \\
$20 \mathrm{~m}$ & $20.09 \mathrm{~m}$ & 8 \\
$30 \mathrm{~m}$ & $29.96 \mathrm{~m}$ & 9 \\
$40 \mathrm{~m}$ & $40.33 \mathrm{~m}$ & 8 \\
$50 \mathrm{~m}$ & $50.08 \mathrm{~m}$ & 10 \\
$60 \mathrm{~m}$ & $60.80 \mathrm{~m}$ & 11 \\
$70 \mathrm{~m}$ & $70.23 \mathrm{~m}$ & 11 \\
$80 \mathrm{~m}$ & $81.66 \mathrm{~m}$ & 9 \\
$90 \mathrm{~m}$ & $91.29 \mathrm{~m}$ & 8 \\
$100 \mathrm{~m}$ & $101.68 \mathrm{~m}$ & 9 \\
\hline
\end{tabular}

TABLE 2: System maximum current consumption.

\begin{tabular}{lc}
\hline Item & Max current \\
\hline CPU1211C DC/DC/DC PLC & $2.9 \mathrm{~A}$ \\
SM-1231 PLC ANALOG CARD & $0.5 \mathrm{~A}$ \\
KTP700 & $0.23 \mathrm{~A}$ \\
LOGO! OBA8 & $3 \mathrm{~A}$ \\
LOGO! CMR2040 & $0.3 \mathrm{~A}$ \\
PHOENIX ETHERNET HUB & $0.5 \mathrm{~A}$ \\
PHOENIX SAFETY BARRIERS $\times 2$ & $0.2 \mathrm{~A}$ \\
VEGAPULS62 $\times 7$ & $0.154 \mathrm{~A}$ \\
MSFG 24-EX SOLENOID VALVE $\times 7$ & $0.17 \mathrm{~A}$ \\
\hline Total & $7.954 \mathrm{~A}$ \\
\hline
\end{tabular}

from 0 to $100 \mathrm{~m}$, which amounts to $0.354 \mathrm{~m}$ at $30 \mathrm{~m}$. The maximum current consumption from the system is listed in Table 2.

The total current consumption adds up to $7.954 \mathrm{~A}$. This means that with a $12 \mathrm{Ah}$ batter capacity the system can stay powered for at least another 1 hour and $30 \mathrm{~min}$.

\section{Conclusion}

The level monitoring system was successfully constructed and tested. Each segment has been fulfilled and level monitoring with alarm notifications has been proved to be possible with the suggested setup. The incorporation of the GPS module for both positioning and route control is made possible through the system and adds tremendous value to user access control and level alarm notification stamping. The system also has a backup battery that allows the system to continue monitoring even when the power from the truck has been interrupted. This assists with system tampering along with control panel door status.

\section{Conflicts of Interest}

The authors declare that there are no conflicts of interest that may arise from this work. 


\section{Acknowledgments}

The authors would like to thank Wynand Kotze (Automation Works) for the project approval and assistance with equipment for proof of concept, Reinhold de Villiers (Automation Works) for assistance with Tank Volume measurement, and Theuns Kotze (Automation Works) for assisting with continuing with tanker trial.

\section{References}

[1] F. Bibi, C. Guillaume, N. Gontard, and B. Sorli, "A review: RFID technology having sensing aptitudes for food industry and their contribution to tracking and monitoring of food products," Trends in Food Science \& Technology, vol. 62, pp. 91-103, 2017.

[2] P.-S. Murvay and I. Silea, "A survey on gas leak detection and localization techniques," Journal of Loss Prevention in the Process Industries, vol. 25, no. 6, pp. 966-973, 2012.

[3] K. Alkhaledi, S. Alrushaid, J. Almansouri, and A. Alrashed, "Using fault tree analysis in the Al-Ahmadi town gas leak incidents," Safety Science, vol. 79, pp. 184-192, 2015.

[4] S. Elaoud, L. Hadj-Taïeb, and E. Hadj-Taïeb, "Leak detection of hydrogen-natural gas mixtures in pipes using the characteristics method of specified time intervals," Journal of Loss Prevention in the Process Industries, vol. 23, no. 5, pp. 637-645, 2010.

[5] S. Scott and M. Barrufet, "Worldwide assessment of industry Leak detection capabilities for single and multiphase pipelines," Tech. Rep., 2003.

[6] J. Doorhy, "Real-time pipeline leak detection and location using volume balancing," Pipeline Gas Journal, vol. 238, no. 2, pp. 6566, 2011.

[7] T. Jespen, "ATEX - Explosive Atmospheres: Risk Assessment, Control and Compliance," Springer International Publishing, pp. 46-52, 2016.

[8] A. Barderas and B. Roadea, "How to calculate the volume of partially full tanks," in Proceedings of the International Journal of Research in Engineering and Technology, pp. 2-7, 2016. 


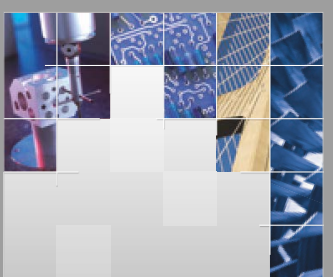

\section{Enfincering}
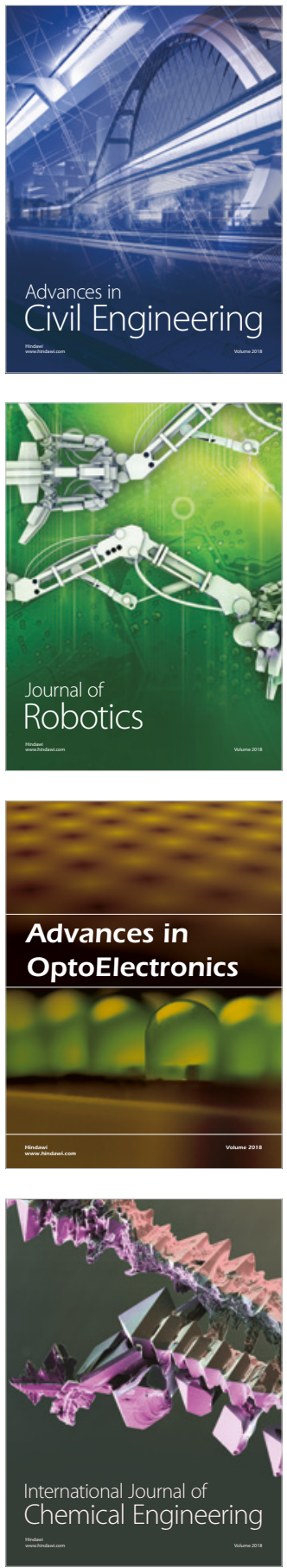

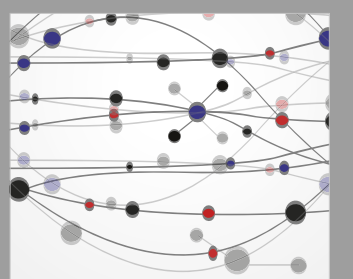

\section{Rotating \\ Machinery}

The Scientific World Journal

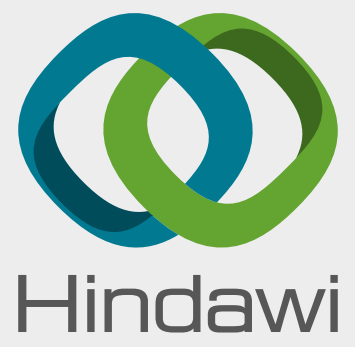

Submit your manuscripts at

www.hindawi.com
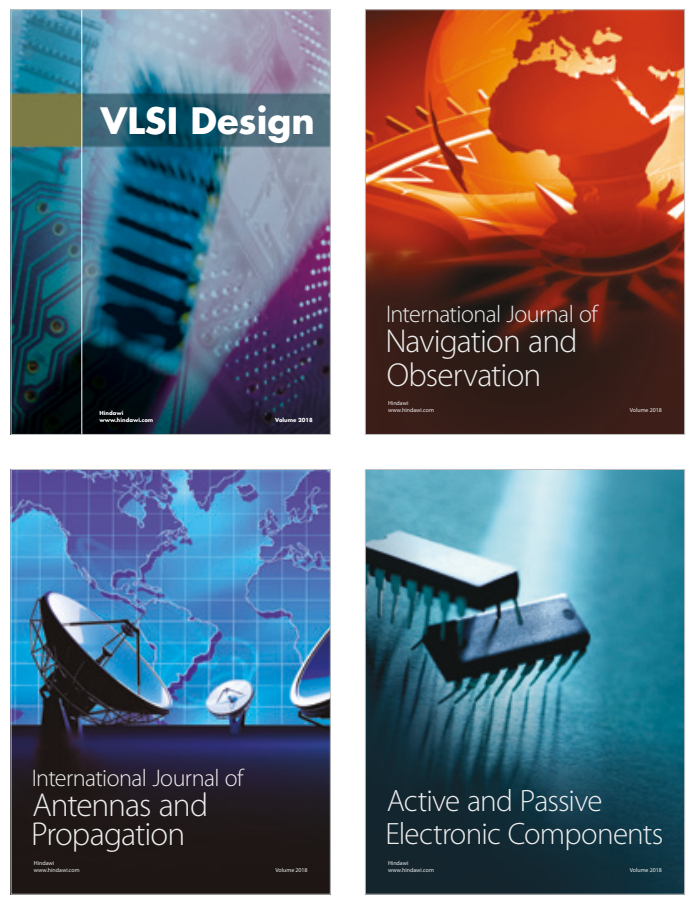
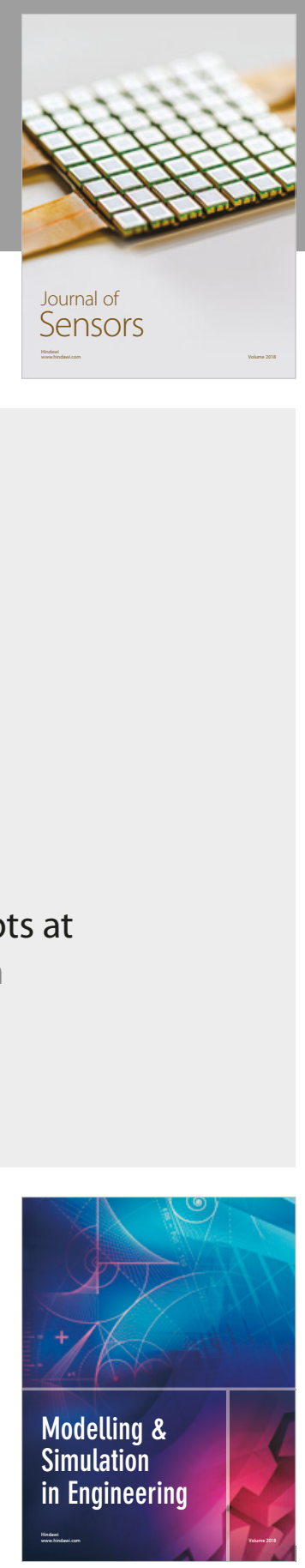

\section{Advances \\ Multimedia}
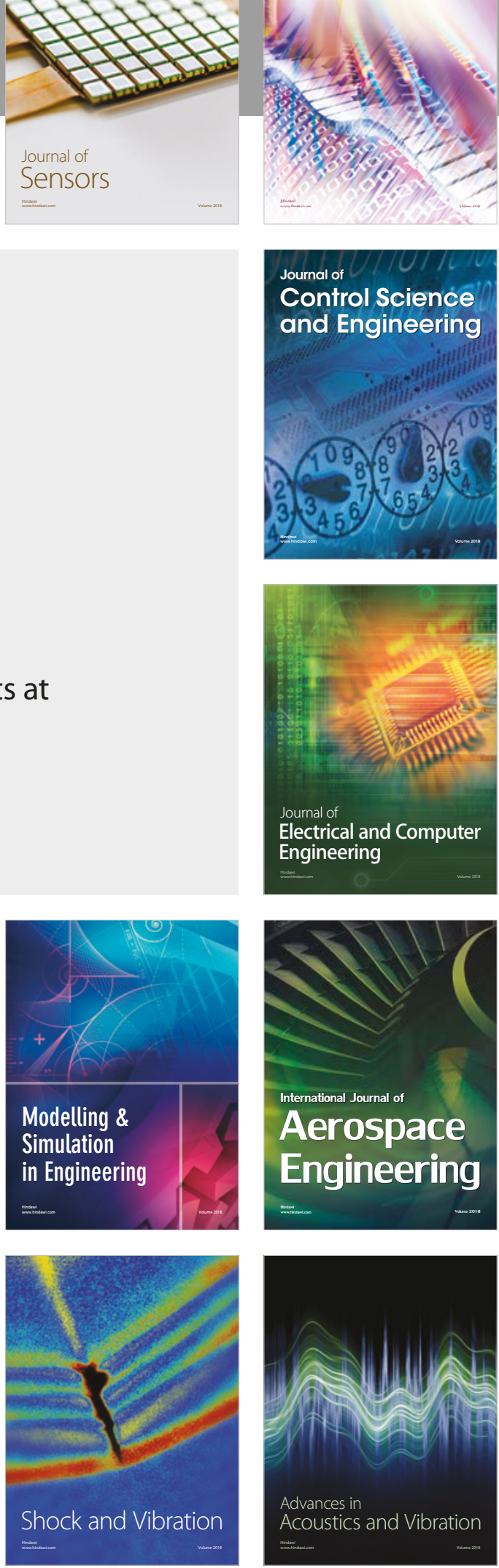